\title{
RASA KELEKATAN ANAK PADA RUANG PUBLIK TERPADU RAMAH ANAK (RPTRA)
}

\author{
Susinety Prakoso ${ }^{1, *}$, Julia Dewi ${ }^{2}$ \\ ${ }^{1}$ Program Studi Arsitektur, Fakultas Desain, Universitas Pelita Harapan, Jl. M.H. Thamrin Boulevard, \\ Lippo Karawaci, Tangerang, 15811 \\ ${ }^{2}$ Program Studi Arsitektur, Fakultas Desain, Universitas Pelita Harapan, JI. M.H. Thamrin Boulevard, \\ Lippo Karawaci, Tangerang, 15811 \\ *susinety.prakoso@uph.edu
}

\begin{abstract}
ABSTRAK. Fakta empiris membuktikan bahwa kehadiran suatu taman lingkungan dapat berkontribusi pada terbentuknya rasa kelekatan seseorang, termasuk anak, pada tempat. Rasa kelekatan anak pada tempat perlu ada dan penting karena memberikan kontribusi positif bagi perkembangan fisik dan mental anak. Tulisan ini bertujuan untuk memahami apakah kehadiran RPTRA, yang secara ekstensif dibangun oleh Pemprov DKI Jakarta sejak tahun 2015, telah berkontribusi pada terbentuknya rasa kelekatan anak pada tempat? Apakah RPTRA telah menjadi tempat favorit anak? Bagaimana rasa kelekatan anak terhadap RPTRA dapat dipahami melalui dimensi pembentuk rasa kelekatan anak pada tempat?
\end{abstract}

Lokasi studi adalah 10 RPTRA yang tersebar di seluruh wilayah Jakarta. Pengukuran dan pemahaman rasa kelekatan anak terhadap RPTRA dilakukan melalui observasi, wawancara dan pengisian kuesioner oleh pengguna anak $(n=597)$ di lokasi RPTRA. Hasil pengukuran menunjukkan $77 \%$ responden anak menyatakan ada rasa kelekatan terhadap RPTRA dan 95\% responden anak memberikan penilaian positif terhadap RPTRA sebagai tempat favorit mereka. Rasa kelekatan anak terhadap RPTRA dibentuk oleh 1) dimensi penggunaan RPTRA secara kolektif oleh anak bersama teman dan keluarga 2) dimensi tempat, seperti: kemudahan akses dan kedekatan lokasi RPTRA dengan rumah tinggal, keamanan, ketersediaan fasilitas ruang luar untuk bermain, dan ketersediaan fasilitas ruang dalam untuk belajar dan melakukan berbagai aktivitas terstruktur yang edukatif; 3 ) Dimensi proses, seperti: peluang untuk melakukan berbagai aktivitas di RPTRA, pengalaman yang berulang bersama teman sebaya dan keluarga, kemudahan pergerakkan bolak balik ke RPTA, dan durasi waktu.

Kata kunci: Ruang Publik Terpadu Ramah Anak (RPTRA), anak, rasa kelekatan pada tempat

ABSTRACT. Empirically, the availability of parks contributed to the development of children's place attachment. Having a sense of place attachment is essential for children's physical and mental well-being. This paper aimed to obtain an understanding whether child-friendly integrated public spaces or called RPTRA, which was initiated and built extensively by The Jakarta City Provincial Government since 2015, had contributed to the development of children's place of attachment and if RPTRA was considered as one of children's favourite place. How children's sense of attachment to RPTRA could be understood using three-dimensional, person-place-process framework.

This paper described a study of ten RPTRA located in Jakarta. We examined and measured children's sense of attachment to RPTRA, based on observation, interviews, and data collected from children ( $n-597)$ who completed on-site questionnaires. The results show that $77 \%$ of children had developed a sense of attachment to RPTRA and $95 \%$ of children had positive feelings towards RPTRA as one of their favourite places. The development of children's sense of attachment to RPTRA: 1) occurs at collective level with peers; 2) is influenced by place dimensions, such as easy access and proximity between RPTRA and home, security, availability of outdoor facilities for playing, and availability of indoor facilities for studying and other educative activities; and 3) is expressed through actions, experiences, repetitive movements or proximity-maintaining behaviors and length of time spend in RPTRA.

Keywords: Child-friendly Integrated Public Spaces (RPTRA), children, place attachment

\section{PENDAHULUAN}

Secara umum, rasa kelekatan seseorang terhadap tempat (place attachment) merupakan suatu konsep yang terintegrasi melingkupi interaksi antara afeksi dan emosi, pengetahuan dan kepercayaan, perilaku dan tindakan terkait dengan tempat [1]. Sedangkan, rasa kelekatan anak pada tempat merupakan rasa kesenangan berada di suatu tempat dan penyesalan atau kesedihan bila harus meninggalkan tempat tersebut. Emosi positif dan negatif tersebut terkait dengan bagaimana anak memaknai hakikat kualitas tempat, bukan hanya karena kebutuhan fisik anak terpenuhi dari tempat tersebut [2].

Fakta empiris membuktikan bahwa kehadiran suatu ruang terbuka publik atau ruang terbuka hijau seperti taman lingkungan, lingkungan alam, prasarana dan sarana taman lingkungan dapat memberikan kontribusi pada hadirnya rasa kelekatan anak pada tempat [3-7]. Seorang anak dapat mengembangkan 
kelekatannya terhadap suatu tempat, seperti taman lingkungan, tergantung pada tanggapan positif kognitif yang diterima olehnya. Pada umumnya, seorang anak memberikan tanggapan positif pada tempat-tempat yang dianggap mereka khusus atau spesial (favorite places) [2, 7-11]. Namun, ada beberapa hal yang mengakibatkan seorang anak tidak mampu memproses kelekatannya pada tempat tertentu. Faktor-faktor yang mengancam kelekatan seorang pada tempat tertentu adalah terjeratnya orang tua dalam perangkat sosial tertentu sehingga mempengaruhi kebebasan anak untuk bergerak [12-14], adanya persepsi negatif anak terhadap lingkungan [15] dan faktor lingkungan tempat tinggal yang tidak mendukung [16] serta ketergantungan pada televisi dan digital media [17].

Penelitian ini bertujuan untuk mengetahui apakah kehadiran taman lingkungan dalam bentuk Ruang Publik Terpadu Ramah Anak atau yang disingkat dengan nama RPTRA, yang dibangun oleh Pemerintah Provinsi DKI Jakarta sejak tahun 2015, telah memberikan kontribusi pada terbentuknya kelekatan anak pada tempat? Apakah RPTRA telah menjadi tempat favorit anak? Bagaimana rasa kelekatan anak terhadap RPTRA dapat dipahami melalui dimensi pembentuk rasa kelekatan anak pada tempat?

\section{Dimensi Pembentuk Place Attachment}

Dalam memahami rasa kelekatan anak pada RPTRA, penelitian ini meminjam kerangka organisasi yang terdiri dari tiga dimensi yang terpisah namun saling tumpang tindih, yang disebut sebagai tripartite model of place attachment [18]. Model ini terdiri dari dimensi orang, proses dan tempat (lihat Gambar 1).

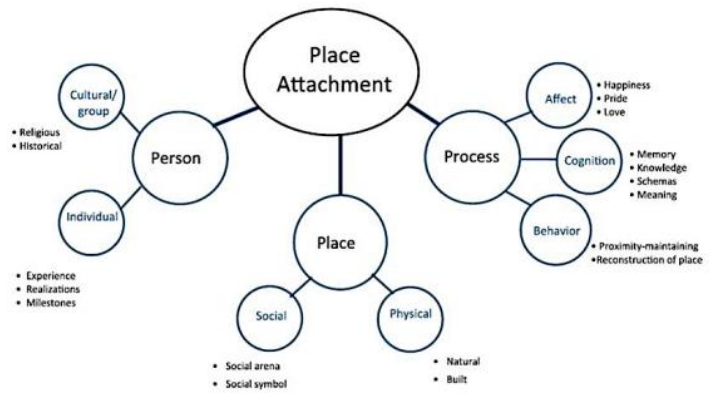

Gambar 1. Tripartite model dari place attachment (Sumber: Scannell and Gifford [18])

Gambar 1 menjelaskan bahwa dimensi pertama yang melibatkan place attachment adalah aktor, yaitu siapa yang lekat dengan tempat itu? Apakah kelekatan tersebut didasarkan pada makna yang diperoleh secara individual ataukah kolektif? Place attachment dapat beroperasi pada tingkat individual maupun kolektif. Makna simbolik terhadap tempat tertentu terkait dengan pengalaman individual atau pengalaman kolektif [18].

Dimensi kedua adalah proses psikologis. Bagaimana afeksi, kognisi dan perilaku termanifestasi dalam kelekatan? Proses psikologis yang terlibat dalam place attachment terdiri dari berbagai kombinasi emosi, kognitif dan perilaku yang terkait dengan tempat tertentu, yang dimunculkan dalam bentuk perasaan kesedihan dan kerinduan bila dipisahkan dari tempat tertentu [18].

Dimensi ketiga adalah kelekatan pada apa? Apa yang menjadi natur dari tempat sehingga mempengaruhi proses kelekatannya? Natur dari suatu tempat dapat dibagi menjadi komponen fisik (rootedness) dan komponen sosial (bondedness) [18].

\section{Pengertian dan Karakteristik RPTRA}

Menurut Peraturan Gubernur Provinsi DKI Jakarta No. 196 Tahun 2015, Ruang Publik Terbuka Ramah Anak (RPTRA) merupakan tempat dan/atau ruang terbuka yang dibangun sebagai wujud komitmen Pemerintah Provinsi Daerah Khusus lbukota Jakarta untuk menjamin terpenuhinya hak anak agar anak dapat hidup, tumbuh, berkembang dan berpartisipasi secara optimal sesuai dengan harkat dan martabat kemanusiaan serta mendapat perlindungan dari kekerasan dan diskriminasi. Keberadaan RPTRA di Jakarta sebagai upaya mendukung Jakarta menjadi Kota Layak Anak.

Berdasarkan Keputusan Gubernur Provinsi Daerah Khusus Ibukota Jakarta Nomor 349 Tahun 2015 Tentang Tim Pelaksana Pembangunan dan Pemeliharaan Ruang Publik Terpadu Ramah Anak, RPTRA ditujukan pada area padat penduduk dengan rasio satu RPTRA untuk setiap Rukun Warga (RW). Menurut Peraturan Gubernur Provinsi DKI Jakarta No. 196 Tahun 2015, RPTRA dibangun dengan tujuan untuk membantu masyarakat, terutama wanita dan anak-anak, yang hidup dalam lingkungan yang sangat padat penduduk. RPTRA bertujuan untuk menyediakan tempat terjadinya berbagai kegiatan dan fungsi ruang publik terintegrasi, seperti bermain dan belajar untuk anak-anak, tempat interaksi sosial bagi warga, tempat konsultasi dan ruang informasi serta edukasi bagi warga, tempat evakuasi dan tempat aktivitas ekonomi yang diselenggarakan oleh 
kelompok ibu-ibu Pokok Pemberdayaan dan Kesejahteraan Keluarga (PKK).

Hingga saat ini, sudah ada 184 RPTRA yang diresmikan oleh pemerintah DKI Jakarta. Namun, hingga kini belum ada studi yang meneliti apakah kehadiran RPTRA telah memberikan kontribusi pada kelekatan seorang anak pada RPTRA tertentu. Penelitian ini mendesak untuk dilakukan agar perencanaan dan pembangunan RPTRA yang telah ada tidak hanya sekedar sebagai pemenuhan pertambahan luasan ruang terbuka hijau di Jakarta, namun juga memiliki kontribusi bagi perkembangan kelekatan anak pada tempat. Hadirnya kelekatan anak pada tempat termasuk RPTRA merupakan landasan bagi seorang anak untuk mengeksplorasi dunianya dan memberikan kontribusi positif bagi perkembangan fisik dan mental anak [1921]. Tanpa adanya rasa kelekatan anak pada suatu tempat, dapat berakibat pada timbulnya rasa asing seseorang pada saat berada di suatu tempat tertentu [22], tidak merasa memiliki lingkungannya, serta tidak peduli pada lingkungannya [19-21].

\section{METODE PENELITIAN}

Penelitian ini memilih 10 (sepuluh) RPTRA (lihat Tabel 1) yang lokasinya mewakili masing-masing wilayah di Jakarta (Lihat Gambar 2).

Tabel 1. Daftar RPTRA

\begin{tabular}{|c|c|c|c|c|}
\hline No & $\begin{array}{c}\text { Nama } \\
\text { RPTRA }\end{array}$ & $\begin{array}{c}\text { Wilayah } \\
\text { Adminstrasi }\end{array}$ & $\begin{array}{l}\text { Luas } \\
\left(\mathrm{m}^{2}\right)\end{array}$ & $\begin{array}{c}\text { Tanggal } \\
\text { Peresmian }\end{array}$ \\
\hline 1 & $\begin{array}{l}\text { Sungai } \\
\text { Bambu }\end{array}$ & $\begin{array}{c}\text { Jakarta } \\
\text { Utara }\end{array}$ & \pm 3838 & $\begin{array}{l}13-05- \\
2015\end{array}$ \\
\hline 2 & $\begin{array}{l}\text { Sunter Jaya } \\
\text { Berseri }\end{array}$ & $\begin{array}{c}\text { Jakarta } \\
\text { Utara }\end{array}$ & \pm 3513 & $\begin{array}{l}18-12- \\
2015\end{array}$ \\
\hline 3 & Bahari & $\begin{array}{l}\text { Jakarta } \\
\text { Selatan }\end{array}$ & \pm 770 & $\begin{array}{l}21-05- \\
2015\end{array}$ \\
\hline 4 & $\begin{array}{l}\text { Bintaro } \\
\text { Permai }\end{array}$ & $\begin{array}{l}\text { Jakarta } \\
\text { Selatan }\end{array}$ & \pm 540 & $\begin{array}{l}30-12- \\
2015\end{array}$ \\
\hline 5 & $\begin{array}{l}\text { Taman } \\
\text { Kenanga }\end{array}$ & $\begin{array}{c}\text { Jakarta } \\
\text { Pusat }\end{array}$ & \pm 2084 & $\begin{array}{l}30-05- \\
2015\end{array}$ \\
\hline 6 & $\begin{array}{l}\text { Karet } \\
\text { Tengsin }\end{array}$ & $\begin{array}{c}\text { Jakarta } \\
\text { Pusat }\end{array}$ & \pm 654 & $\begin{array}{l}30-12- \\
2015\end{array}$ \\
\hline 7 & Kembangan & $\begin{array}{c}\text { Jakarta } \\
\text { Barat }\end{array}$ & \pm 3250 & $\begin{array}{l}10-06- \\
2015\end{array}$ \\
\hline 8 & $\begin{array}{l}\text { Meruya } \\
\text { Utara }\end{array}$ & $\begin{array}{c}\text { Jakarta } \\
\text { Barat }\end{array}$ & \pm 4994 & $\begin{array}{l}29-12- \\
2015 \\
\end{array}$ \\
\hline 9 & Cililitan & $\begin{array}{c}\text { Jakarta } \\
\text { Timur }\end{array}$ & \pm 2642 & $\begin{array}{l}22-10- \\
2015\end{array}$ \\
\hline 10 & $\begin{array}{l}\text { Pulogebang } \\
\text { Indah }\end{array}$ & $\begin{array}{c}\text { Jakarta } \\
\text { Timur }\end{array}$ & \pm 3642 & $\begin{array}{l}23-12- \\
2015\end{array}$ \\
\hline
\end{tabular}

Sumber: http://data.jakarta.go.id/

RPTRA yang dipilih adalah RPTRA yang telah digunakan oleh warga minimal 12 bulan. Dimensi waktu menjadi salah satu dasar pertimbangan pemilihan lokasi RPTRA karena dimensi waktu menentukan proses bagaimana seorang anak mengembangkan kelekatan pada tempat [21, 23].

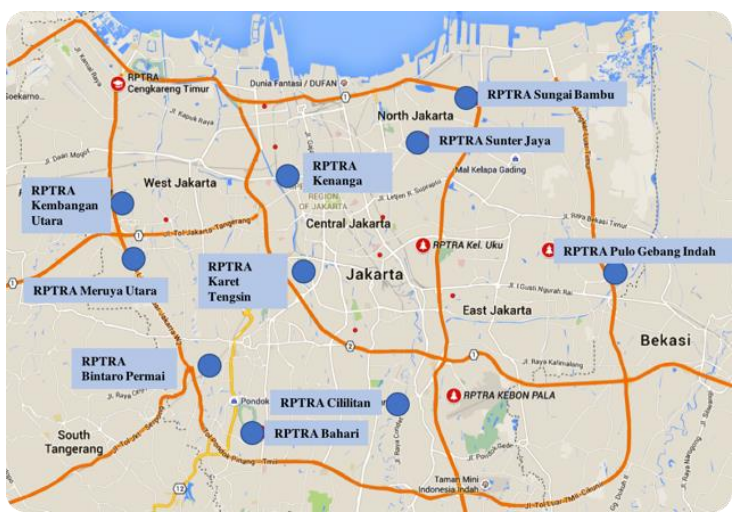

Gambar 2. Lokasi RPTRA

Anak yang menjadi subjek penelitian adalah minimal usia sekolah dasar (6-11 tahun) hingga remaja (12-17 tahun). Usia sekolah dasar merupakan usia, di mana seorang anak menggunakan ruang terbuka secara ekstensif [2] dan merupakan usia di mana pondasi kelekatan terhadap tempat sudah diletakkan $[21,24]$.

Data penelitian dikumpulkan sejak akhir Juni hingga pertengahan Oktober 2017. Setiap RPTRA telah dikunjungi 7-9 kali dalam kurun waktu 13-15 minggu pengambilan data. Kunjungan dilakukan pada saat akhir pekan dan sore hari dimana RPTRA lebih banyak digunakan oleh anak-anak. Dalam setiap kunjungan, calon responden anak yang potensial didekati agar bersedia berpartisipasi dalam penelitian ini. Bila disetujui, calon tersebut diberikan kuesioner untuk di isi di lokasi.

Ada 2 perangkat kuesioner yang digunakan dalam penelitian ini. Kuesioner pertama dikembangkan dari studi Peschardt, Schipperijn and Stigsdotter [25] dan digunakan untuk mengetahui siapa dan bagaimana anak menggunakan RPTRA. Kuesioner kedua dikembangkan dari studi yang dilakukan oleh Lewicka [26] dan Williams and Vaske [27], dan digunakan untuk mengukur tingkat kelekatan anak pada RPTRA. Tingkat kelekatan anak terhadap RPTRA diukur dengan menggunakan 12 kriteria. Masing-masing kriteria dipresentasikan dalam bentuk struktur semipolar yang diadaptasi dari Shamai and Ilatov [28]. Setiap kriteria dijawab oleh anak dengan memilih jawaban sikap positif "ya", "biasa saja", dan "tidak". Penggunaan jawaban sikap yang sederhana membuat penelitian ini dapat 
menangkap rasa kelekatan anak terhadap RPTRA secara langsung.

Selain kuesioner, teknik pengumpulan data juga mengandalkan observasi dan wawancara dengan anak dan pengelola RPTRA. Tujuannya adalah untuk memahami kondisi fisik RPTRA dan memahami dimensi proses pembentuk rasa kelekatan anak pada RPTRA.

\section{HASIL DAN PEMBAHASAN}

\section{Profil Anak Pengguna RPTRA}

Dari keseluruhan RPTRA yang diteliti, penelitian ini menjaring 597 anak pengguna RPTRA, dengan komposisi seperti yang terlihat pada Tabel 2.

Tabel 2. Profil responden anak

\begin{tabular}{|c|c|}
\hline Anak (n) & 597 \\
\hline Laki-Laki & $38 \%$ \\
\hline Perempuan & $62 \%$ \\
\hline \multicolumn{2}{|l|}{ Usia } \\
\hline $6-11$ & $65 \%$ \\
\hline $12-17$ & $35 \%$ \\
\hline
\end{tabular}

Berdasarkan analisis frekuensi penggunaan RPTRA oleh anak (lihat Tabel 3), pada umumnya anak diijinkan oleh orang tuanya mengunjungi RPTRA sendiri (95\%), karena dekat rumah dan dianggap aman.

Tabel 3. Analisis frekuensi penggunaaan RPTRA oleh anak

\begin{tabular}{|c|c|}
\hline \multicolumn{2}{|c|}{$\begin{array}{l}\text { Apakah diijinkan orang tua untuk datang ke } \\
\text { RPTRA ini sendiri? (\%) }\end{array}$} \\
\hline Ya, karena dekat rumah dan aman & $95 \%$ \\
\hline $\begin{array}{l}\text { Tidak, karena saya dianggap terlalu } \\
\text { kecil }\end{array}$ & $5 \%$ \\
\hline \multicolumn{2}{|c|}{ Dengan apa kamu datang ke RPTRA ini? (\%) } \\
\hline Kendaraan umum & $2 \%$ \\
\hline Kendaraan pribadi/motor & $16 \%$ \\
\hline Sepeda & $9 \%$ \\
\hline Jalan kaki & $73 \%$ \\
\hline \multicolumn{2}{|c|}{ Dengan siapa kamu datang ke RPTRA ini? (\%) } \\
\hline sendiri & $15 \%$ \\
\hline keluarga & $10 \%$ \\
\hline teman & $75 \%$ \\
\hline \multicolumn{2}{|l|}{ Mengapa kamu datang ke RPTRA ini? (\%) } \\
\hline Bertemu teman & $8 \%$ \\
\hline Olah raga & $12 \%$ \\
\hline Bermain & $31 \%$ \\
\hline
\end{tabular}

Rekreasi $6 \%$

Istirahat \& menyegarkan diri $\quad 12 \%$

belajar $18 \%$

membaca di perpustakaan $\quad 9 \%$

Lainnya: menari, menggambar, $\quad 4 \%$ mengikuti kegiatan

Berapa lama kira-kira waktu yang dibutuhkan untuk sampai ke RPTRA ini? (\%)

5-10 menit jalan kaki 52\%

5-10 menit naik sepeda $\quad 5 \%$

5-10 menit naik motor $\quad 12 \%$

tidak tahu $31 \%$

Seberapa sering kamu mengunjungi RPTRA ini? (\%)

Beberapa kali dalam sehari $\quad 7 \%$

setiap hari $38 \%$

satu kali seminggu $\quad 8 \%$

beberapa kali dalam seminggu $\quad 15 \%$

beberapa kali dalam sebulan $\quad 2 \%$

jarang/kadang-kadang 26\%

baru pertama kali $\quad 1 \%$

jika ada acara/kegiatan di RPTRA $\quad 3 \%$

Sejak kapan kamu mulai mengunjugi RPTRA ini? (\%)

Sejak tempat ini diresmikan (1-2 tahun $\quad 74 \%$

lalu)

Sejak beberapa bulan lalu $\quad 16 \%$

Sejak beberapa minggu lalu $\quad 10 \%$

Apa waktu yang biasanya dipilih untuk berkunjung ke RPTRA? (\%)

\begin{tabular}{lr} 
Pagi & $12 \%$ \\
siang & $22 \%$ \\
sore & $43 \%$ \\
malam & $7 \%$ \\
akhir pekan & $6 \%$ \\
hari libur nasional & $5 \%$ \\
\hline Berapa lama biasanya berada di RPTRA ini? $(\%)$ \\
\hline kurang dari 5 menit & $3 \%$ \\
kira-kira 15 menit & $11 \%$ \\
kira-kira 30 menit & $12 \%$ \\
kira-kira 1 jam & $16 \%$ \\
1-2 jam & $29 \%$ \\
Lebih dari 2 jam & $29 \%$ \\
\hline
\end{tabular}

Berdasarkan data pada Tabel 3, 73\% anak berjalan kaki ke RPTRA bersama teman $(75 \%)$ setiap hari $(38 \%)$, sejak tempat itu diresmikan 1-2 tahun yang lalu (74\%). Waktu yang dipilih anak untuk menggunakan RPTRA adalah 
siang hari (22\%) dan sore hari (43\%) setelah pulang sekolah. Ada $58 \%$ anak menyatakan bahwa mereka menghabiskan waktu di RPTRA selama 1-2 jam bahkan lebih. Lima alasan utama anak menggunakan RPTRA adalah untuk bermain di playground (31\%), belajar $(18 \%)$, berolah raga seperti bermain bola, main sepeda, berlari (12\%), beristirahat serta menyegarkan diri (12\%) dan membaca di perpustakaan (9\%).

Kebanyakan anak (57\%) tinggal dalam jarak 510 menit berjalan kaki dan bersepeda dari RPTRA, serta $12 \%$ anak tinggal dalam jarak 510 menit naik motor dari RPTRA. Hasil ini mengindikasikan bahwa ada korelasi kedekatan RPTRA dan tempat tinggal anak dengan tingginya frekuensi anak menggunakan RPTRA setiap hari bahkan beberapa kali dalam seminggu.

Fasilitas RPTRA yang paling banyak digunakan oleh anak-anak (Lihat Tabel 4) adalah perpustakaan (31\%) untuk belajar dan membaca, taman bermain (25\%), ruang serbaguna atau aula (17\%) dan area lapangan futsal $(15 \%)$.

Tabel 4. Fasilitas RPTRA yang sering digunakan oleh anak

\begin{tabular}{lr}
\hline \multicolumn{2}{l}{ Fasilitas RPTRA yang paling sering digunakan oleh } \\
anak (\%) \\
\hline Area Lapangan futsal & $15 \%$ \\
Area Tempak duduk (balai, & $5 \%$ \\
musholla, amphitheatre) & $25 \%$ \\
Taman Bermain (playground) & $31 \%$ \\
Perpustakaan & $17 \%$ \\
Ruang serbaguna (aula) & $2 \%$ \\
Halaman hijau (rumput) & $3 \%$ \\
Lainnya: toilet, taman refleksi
\end{tabular}

Rasa Kelekatan Anak terhadap RPTRA

Penelitian ini menemukan bahwa rata-rata $77 \%$ responden anak menyatakan ada rasa kelekatan terhadap RPTRA (Lihat Tabel 5).

Rata-rata $77 \%$ anak menyatakan ada rasa kelekatan terhadap RPTRA menunjukkan adanya korelasi dengan data lama kunjungan dan durasi kunjungan. Data pada Tabel 3 menunjukkan bahwa $68 \%$ anak mengunjungi RPTRA dalam frekuensi tinggi (beberapa kali dalam sehari hingga beberapa kali dalam seminggu) dan $74 \%$ anak telah mengalami dan menggunakan RPTRA sejak diresmikan 12 tahun lalu hingga sekarang.
Tabel 5. Tingkat kelekatan anak terhadap RPTRA

\begin{tabular}{|c|c|c|c|c|}
\hline & \multirow{3}{*}{ Ya } & \multirow{3}{*}{$\begin{array}{c}\text { Biasa } \\
\text { saja } \\
15 \%\end{array}$} & \multirow{3}{*}{$\begin{array}{l}\text { Tidak } \\
4 \%\end{array}$} \\
\hline & 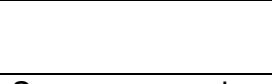 & & & \\
\hline 1 & $\begin{array}{l}\text { Saya mengenal } \\
\text { orang-orang yang } \\
\text { berada di RPTRA } \\
\text { ini dan } \\
\text { fasilitasnya } \\
\text { dengan baik }\end{array}$ & & & \\
\hline 2 & $\begin{array}{l}\text { Saya merasa } \\
\text { aman dan } \\
\text { nyaman di } \\
\text { RPTRA ini }\end{array}$ & $91 \%$ & $8 \%$ & $1 \%$ \\
\hline 3 & $\begin{array}{l}\text { Saya merasa } \\
\text { betah di RPTRA } \\
\text { ini }\end{array}$ & $78 \%$ & $21 \%$ & $1 \%$ \\
\hline 4 & $\begin{array}{l}\text { Saya merasa } \\
\text { RPTRA ini bagian } \\
\text { dari diri saya }\end{array}$ & $64 \%$ & $31 \%$ & $5 \%$ \\
\hline 5 & $\begin{array}{l}\text { Saya merasa } \\
\text { bangga dengan } \\
\text { keberadaan } \\
\text { RPTRA ini }\end{array}$ & $85 \%$ & $14 \%$ & $1 \%$ \\
\hline 6 & $\begin{array}{l}\text { Saya merasa } \\
\text { senang/gembira } \\
\text { bila ada di } \\
\text { RPTRA ini }\end{array}$ & $86 \%$ & $12 \%$ & $2 \%$ \\
\hline 7 & $\begin{array}{l}\text { Saya } \\
\text { meninggalkan } \\
\text { RPTRA ini } \\
\text { dengan perasaan } \\
\text { senang }\end{array}$ & $65 \%$ & $23 \%$ & $12 \%$ \\
\hline 8 & $\begin{array}{l}\text { Saya merasa } \\
\text { sedih dan } \\
\text { rindu/kangen bila } \\
\text { tidak bisa datang } \\
\text { ke RPTRA ini }\end{array}$ & $58 \%$ & $35 \%$ & $7 \%$ \\
\hline 9 & $\begin{array}{l}\text { Saya merasa } \\
\text { sedih/kecewa bila } \\
\text { harus kehilangan } \\
\text { RPTRA ini }\end{array}$ & $68 \%$ & $26 \%$ & $6 \%$ \\
\hline 10 & $\begin{array}{l}\text { Saya peduli } \\
\text { dengan RPTRA } \\
\text { ini }\end{array}$ & $83 \%$ & $16 \%$ & $1 \%$ \\
\hline 11 & $\begin{array}{l}\text { Di RPTRA ini } \\
\text { saya dapat } \\
\text { melakukan } \\
\text { kegiatan yang sya } \\
\text { suka }\end{array}$ & $92 \%$ & $6 \%$ & $2 \%$ \\
\hline \multirow[t]{2}{*}{12} & $\begin{array}{l}\text { Tidak ada tempat } \\
\text { lain yang lebih } \\
\text { baik untuk } \\
\text { beraktivitas di } \\
\text { lingkungan rumah } \\
\text { tinggal saya, } \\
\text { selain di RPTRA } \\
\text { ini }\end{array}$ & $72 \%$ & $21 \%$ & $7 \%$ \\
\hline & Rata-rata & $77 \%$ & $19 \%$ & $4 \%$ \\
\hline
\end{tabular}

Jadi, penelitian ini mengkonfirmasi bahwa durasi atau waktu berpengaruh secara positif pada perkembangan rasa kelekatan anak terhadap tempat [21, 23] dan place attachment secara umumnya [20]. Penelitian ini juga 
menemukan bahwa adanya rasa kelekatan anak terhadap RPTRA dikonstruksikan dalam berbagai aktivitas secara berulang-ulang setiap hari atau setiap minggu sejak 1-2 tahun yang lalu hingga sekarang.

Rasa kelekatan anak terhadap RPTRA, atau yang disebut dengan long-term affective bond adalah merupakan manifestasi dari kesadaran siklus pola interaksi yang timbul dari sistem perilaku kelekatan dan sistem motivasi tuntutan eksplorasi anak terhadap tempat [29]. Rasa kelekatan anak terhadap RPTRA ini dimungkin untuk berkembang karena adanya pengalaman positif yang berulang yang dirasakan anak pada saat berada di RPTRA [29]. Rasa kelekatan anak terhadap RPTRA juga berkembang karena adanya pengalaman bermain, eksplorasi dan interaksi sensori dengan tempat. Jika seorang anak secara berulang merasakan kesenangan dalam mengalami tempat, maka ikatan emosional akan terbentuk antara anak dan tempat.

Tingginya rata-rata rasa kelekatan anak pada RPTRA (77\%) seperti yang ditunjukkan pada Tabel 4 sebelumnya, dikonfirmasi dengan penilaian umum yang diberikan anak terhadap RPTRA. Secara umum, hasil pengukuran menunjukkan bahwa total ada $95 \%$ responden anak memberikan penilaian positif $(+1 \mathrm{~s} / \mathrm{d}+5)$ terhadap RPTRA sebagai tempat favorit mereka (Lihat Gambar 3).

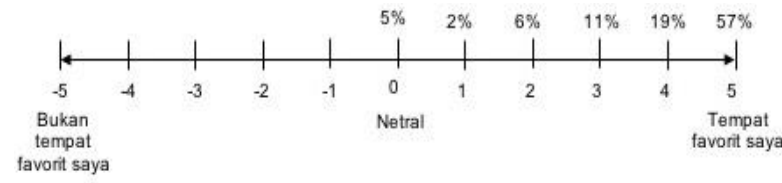

Gambar 3. Penilaian anak terhadap RPTRA sebagai tempat favorit

Tingginya rasa kelekatan anak terhadap RPTRA (77\%) dan penilaian positif RPTRA sebagai tempat favorit oleh $95 \%$ anak, menunjukkan bahwa anak telah berhasil membentuk ikatan emosional dengan RPTRA karena kualitas RPTRA dan berulangnya tingkat kepuasan atau kesenangan emosional anak pada saat berada di RPTRA.

\section{Dimensi Pembentuk Rasa Kelekatan Anak pada RPTRA}

Penelitian ini berupaya untuk memahami rasa kelekatan anak terhadap RPTRA dan berhasilnya RPTRA sebagai tempat favorit anak dengan menggunakan tiga dimensi place attachment yang terpisah namun saling tumpang tindih [18]. Penelitian ini menemukan bahwa RPTRA sebagai ruang terbuka hijau publik berskala kecil (small public urban open space), mampu memberikan kontribusi terhadap rasa kelekatan anak terhadap tempat. Temuan ini sesuai dengan hasil penelitan $\mathrm{Ji}$ [30] yang menyatakan bahwa kehadiran taman lingkungan akan memberikan dampak kelekatan seseorang pada tempat.

Seluruh RPTRA yang diteliti berada di lingkungan perumahan yang sangat padat penduduk, seperti kampung kota dan rumah susun. Berdasarkan hasil observasi, setiap RPTRA mudah diakses, dan dilengkapi dengan penanda dan informasi terkait nama RPTRA, jam operasional RPTRA, peraturan RPTRA, pengelolaan RPTRA, aktivitas dan program-program terencana RPTRA. Kondisi RPTRA dalam keadaan baik, terawat dan dimonitor serta dikelola setiap harinya oleh enam orang pengelola secara bergantian. Setiap RPTRA dikelilingi oleh pagar dan memiliki pintu masuk yang dapat dibuka dan dikunci sesuai dengan jam operasional taman. Kondisi lingkungan sekitar RPTRA dapat dilihat pada Gambar 4.

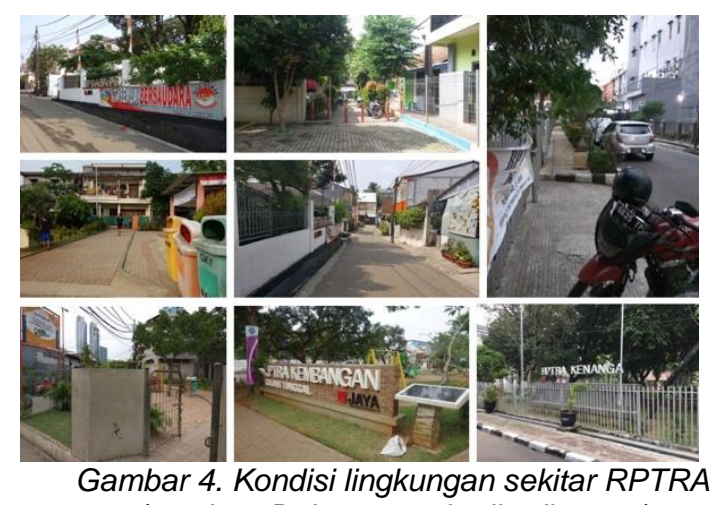

(sumber: Dokumentasi pribadi, 2017)

Secara umum, RPTRA memiliki fasilitas generik yang telah ditetapkan oleh pemerintah provinsi DKI Jakarta. Fasilitas ruang luar (Lihat Gambar 5) RPTRA terdiri dari: lapangan olah raga, area bermain, amphitheater, jogging track, jalur refleksi kaki, taman obat keluarga atau Taman Toga dan kolam gizi. 


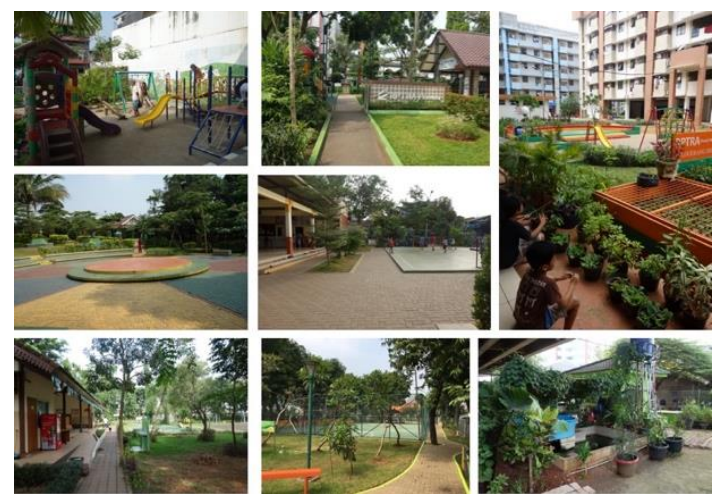

Gambar 5. Fasilitas ruang luar RPTRA (sumber: Dokumentasi pribadi, 2017)

RPTRA memiliki fasilitas ruang dalam (Lihat Gambar 6) seperti: ruang serbaguna/aula, perpustakaan, ruang laktasi, ruang pengelola, toilet pria, toilet wanita, toilet anak dan toilet disabel, tempat cuci tangan, pantry dan gudang.

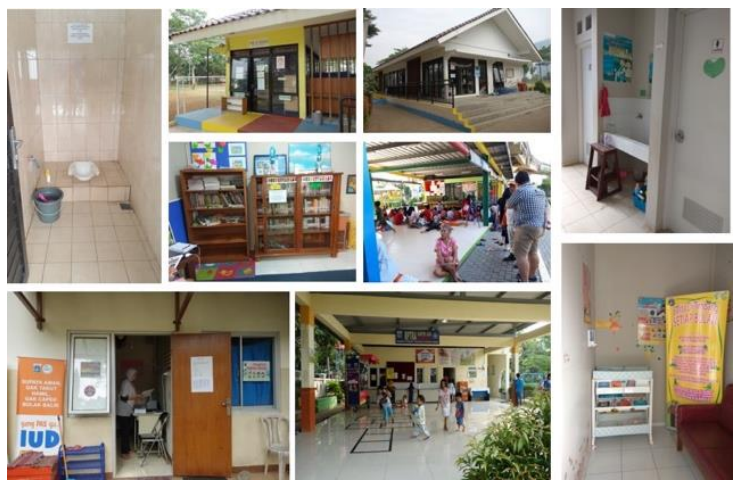

Gambar 6. Fasilitas ruang dalam RPTRA

(sumber: Dokumentasi pribadi, 2017)

Penelitian ini menemukan bahwa RPTRA berhasil menjadi attachment figure bagi anak, karena RPTRA memiliki kualitas dimensi fisik (place dimension), seperti:

a. Kemudahan akses dan kedekatan lokasi RPTRA dengan rumah tinggal.

b. Ketersediaan fasilitas ruang luar untuk bermain (playground), taman hijau, dsb, serta ketersediaan fasilitas ruang dalam seperti aula/serbaguna dan perpustakaan untuk belajar dan untuk menampung berbagai aktivitas edukasi dan seni yang rutin diadakan di RPTRA. Kualitas ini penting bagi RPTRA, karena tempat yang menyediakan peluang bagi anak untuk bereksplorasi dan berekspresi secara kreatif berkontribusi pada kelekatan anak terhadap tempat [2, 31].

c. Keamanan RPTRA melalui ketersediaan pagar pengaman, pintu masuk, CCTV dan pengelola RPTRA. Seperti yang dinyatakan oleh Chawla [2], Day [31] bahwa agar suatu tempat dapat menjadi tempat favorit, maka tempat tersebut perlu menyediakan rasa aman.

d. Memiliki pintu masuk yang jelas terlihat dan mudah diakses.

Hasil temuan kualitas dimensi fisik ini sesuai dengan hasil penelitian Prakoso [32] yang menemukan bahwa lingkungan binaan yang dapat mendukung kelekatan anak, maka lingkungan binaan termasuk RPTRA perlu memiliki beberapa kualitas karakteristik spasial yang mendukung, seperti:

a. ruang terbuka yang berpotensi untuk digunakan oleh anak bermain dan bereksplorasi dengan aman dan nyaman.

b. Ruang terbuka yang mudah dijangkau agar rute dan pergerakkan anak dari rumah ke ruang terbuka tertentu dapat selalu berlangsung tanpa hambatan.

c. Ruang terbuka yang memberikan berbagai sensasi sensori yang menyenangkan.

d. Ruang terbuka yang memberikan kesempatan bagi anak untuk menyegarkan diri (restorasi), dan memiliki berbagai dukungan sosial (baik dari orang tua, teman sebaya dan masyarakat sekitar) bagi anak bersosialisasi.

RPTRA berhasil menjadi tempat favorit anak, tidak hanya dipengaruhi oleh dimensi fisiknya. Dimensi sosial RPTRA juga terbukti mempengaruhi kelekatan anak terhadap RPTRA. Penelitian ini menemukan bahwa $85 \%$ anak menggunakan RPTRA secara kolektif dengan teman dan keluarga. Penggunaan RPTRA dilakukan anak tidak sendirian, namun secara kolektif dengan teman sebaya dan keluarga. Tindakan yang dilakukan anak bersama-sama dengan teman sebaya dan keluarga di tempat dapat memberikan dampak pada perkembangan kelekatan $[21,33,34]$.

Dimensi proses place attachment merupakan kombinasi emosi, kognitif dan perilaku atau tindakan yang terkait dengan tempat tertentu [18]. Proses bagaimana seorang anak dapat mengembangkan rasa kelekatannya pada tempat tertentu tergantung pada tindakan yang dilakukan anak di tempat, seperti aktivitas yang dilakukan bersama-sama dengan teman sebaya dan keluarga [21, 33-35], tergantung pada pergerakkan yang terjadi di tempat [36, 37], dan dimensi waktu. Pengalaman yang berulang pada kurun waktu tertentu baik dilakukan sendiri maupun bersama dengan orang lain (seperti orang tua, guru dan teman sebaya) terbukti memberikan pengaruh dalam perkembangan kelekatan terhadap tempat [21]. 
Hasil penelitian menemukan bahwa proses bagaimana anak dapat mengembangan kelekatannya pada RPTRA, dipengaruhi oleh dimensi fisik RPTRA sebagai attachment figure yang aman dan nyaman. Selain itu, dipengaruhi juga oleh berbagai aktivitas yang ditawarkan oleh RPTRA dan ketersediaan fasilitas yang dimiliki RPTRA untuk dapat menampung berbagai kebutuhan anak untuk bermain, belajar dan bersosialisasi. Berbagai aktivitas terencana dan terstruktur disediakan oleh pengelola RPTRA, seperti latihan menari, latihan pencak silat, membaca, bermain lego, menggambar, mengaji, senam sehat, latihan mendongeng, latihan membaca pusi, dsb. Aktivitas-aktivitas tersebut mendorong dan memotivasi anak untuk menggunakan dan mengalaminya. Ketersediaan berbagai aktivitas yang terencana dan rutin tersebut dimungkinkan karena keaktivan pengelola untuk menjalin kerjasama dengan berbagai dinas terkait, seperti dinas olah raga, dinas kepariwisataan dan perusahaan swasta. Suasana aktivitas di RPTRA dapat dilihat pada Gambar 7.

Hasil penelitian juga menemukan bahwa dimensi proses yang mempengaruhi kelekatan anak pada tempat dipengaruhi pula oleh pergerakkan. Jarak rumah tinggal dengan RPTRA yang mudah dijangkau dengan berjalan kaki 5-10 menit dan dalam radius 0 $500 \mathrm{~m}$, memudahkan anak bergerak bolak balik menggunakan RPTRA. Durasi menggunakan RPTRA yang cukup lama yaitu 1-2 jam bahkan lebih mempengaruhi pengalaman dan rasa kelekatan anak pada RPTRA.

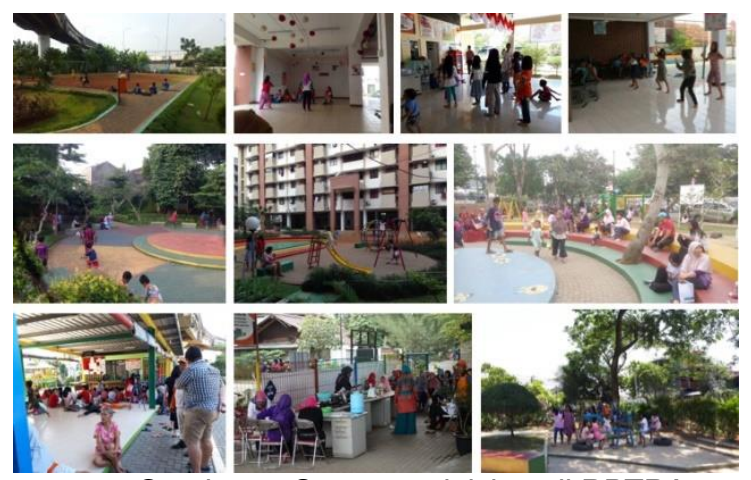

Gambar 7. Suasana aktivitas di RPTRA (sumber: Dokumentasi pribadi, 2017)

Jadi, dimensi proses yang berkontribusi pada rasa kelekatan anak terhadap RPTRA adalah:

a. Aktivitas terencana dan rutin yang diselenggarakan oleh pengelola RPTRA. Aktivitas rutin dan terencana ini mendorong berulangnya pengalaman anak-anak dengan RPTRA. b. Waktu yang dihabiskan di RPTRA cukup lama, sekitar 1-2 jam bahkan lebih.

c. Pengenalan anak dengan RPTRA telah terbentuk untuk jangka waktu yang cukup lama, sekitar 1-2 tahun yang lalu atau sejak RPTRA diresmikan hingga sekarang.

d. Kedekatan lokasi rumah tinggal anak dengan RPTRA dan aktivitas terencana di RPTRA serta adanya kebutuhan anak untuk bermain, belajar dan olah raga di RPTRA mendorong tingginya frekuensi pergerakkan bolak balik anak ke RPTRA.

\section{KESIMPULAN}

Penelitian ini menyimpulkan bahwa: $77 \%$ anak menyatakan ada rasa kelekatan terhadap RPTRA dan $95 \%$ anak memberikan penilaian positif terhadap RPTRA sebagai tempat favorit mereka. Kesimpulan ini mengindikasikan bahwa keberadaan RPTRA adalah merupakan aset bernilai dalam keseharian anak-anak, terutama mereka yang tinggal di lingkungan padat. Oleh karenanya, inisiatif pembangunan satu RPTRA untuk setiap RW perlu secara konsisten dilakukan.

Rasa kelekatan anak terhadap RPTRA dibentuk oleh:

a. Dimensi penggunaan RPTRA secara kolektif oleh anak bersama teman dan keluarga.

b. Dimensi fisik RPTRA, seperti: kemudahan akses dan kedekatan lokasi RPTRA dengan rumah tinggal, keamanan, ketersediaan fasilitas ruang luar untuk bermain, dan ketersediaan fasilitas ruang dalam untuk belajar dan melakukan berbagai aktivitas terstruktur yang edukatif.

c. Kekerabatan dengan teman dan keluarga merupakan dimensi sosial RPTRA yang berkontribusi pada kelekatan anak pada tempat.

d. Dimensi proses, seperti: peluang untuk melakukan berbagai aktivitas di RPTRA, pengalaman yang berulang bersama teman sebaya dan keluarga, kemudahan pergerakkan bolak balik ke RPTA, dan durasi waktu.

Kesimpulan ini mengindikasikan, bahwa kerangka tiga dimensi place attachment [18] dapat digunakan dalam memahami kompleksitas terbentuknya rasa kelekaan anak pada RPTRA. Masih diperlukan penelitian lanjutan untuk memahami lebih mendalam dimensi proses terjadinya rasa kelekatan anak terhadap tempat melalui wawancara lebih mendalam bersama anak, orang tua dan pengelola. 


\section{UCAPAN TERIMA KASIH}

Penelitian ini merupakan bagian dari Penelitian Produk Terapan Tahun Anggaran 2017 yang didanai oleh DRPM Kemenristekdikti dengan kontrak No.049/K3/KM/2017.

\section{DAFTAR PUSTAKA}

[1] Altman, I dan Low, S. M. (1992). Place Attachment: A Conceptual Inquiry. New York: Plenum Press

[2] Chawla, L. (1992). Childhood Place Attachments. London: Plenum.

[3] Corraliza, J A, Collado, S, and Bethelmy L.(2012). Nature as a Moderator of Stress in Urban Children. Procedia - Social and Behavioral Sciences. Vol 38: 253-263.

[4] Loukaitou-Sideris, A. dan Sideris, A. (2009). What Brings Children to the Park? Analysis and Measurement of the Variables Affecting Children's Use of Parks. Journal of the American Planning Association. Vol 76: 89-107.

[5] Veitch, J, Salmon, J dan Ball, K. (2007). Children's Perceptions of the Use of Public Open Spaces for Active Free-Play. Children's Geographies. Vol 5: 409-422.

[6] Davison, K. K. dan Lawson, C. T. (2006). Do Attributes in the Physical Environment Influence Children's Physical Activity? A Review of the Literature. International Journal of Behavioral Nutrition and Physical Activity. Vol 3: 19.

[7] Korpela, K., Kytta, M. dan Hartig, T. (2002). Restorative Experience, Selfregulation, and Children's Place Preferences. Journal of Environmental Psychology. Vol 22: 387-398.

[8] Korpela, K. (2002). Children's Environment. New York: John Wiley \& Sons, Inc. Hal. 363-373.

[9] Elsley, S. (2004). Children's Experience of Public Space. Children \& Society. Vol 18: 155-164.

[10] Derr, T. (2006). 'Sometimes Birds Sound Like Fish': Perspective on Chidren's Place Experience. Cambridge: Cambridge University Press.

[11] Kytta M (2006) Environmental ChildFriendliness in the Light of the Bullerby Model. Cambridge: Cambridge University Press.

[12] Tranter, P. (2006). Overcoming Social Traps: A Key to Creating Child-Friendly Cities. New York: Routledge.

[13] Faulkner, G., Mitra, R., Buliung, R., Fusco, C. dan Stone, M. (2015). Children's outdoor playtime, physical activity, and parental perceptions of the neighbourhood environment. International Journal of Play. Vol 4: 8497.

[14] Refshauge, A. D., Stigsdotter, U. K. dan Cosco, N. G. (2012). Adults' motivation for bringing their children to park playgrounds. Urban forestry \& urban greening. Vol 11: 396-405.

[15] Chawla, L., dan Malone, K. eds. (2003). Neighborhood Quality in Children Eye. Routledge.

[16] Aziz, N. F. and Said, I. (2012). The Trends and Influential Factors of Children's Use of Outdoor Environments: A review. Procedia - Social and Behavioral Sciences. Vol 38: 204-212.

[17] Clements, R. (2004). An Investigation of the Status of Outdoor Play. Contemporary Issues in Early Childhood. Vol 5: 68-80.

[18] Scannell, L. dan Gifford, R. (2010). Defining Place Attachment: A Tripartite Organizing Framework. Journal of Environmental Psychology. Vol 30: 110.

[19] Rollero, C. dan De Piccoli, N. (2010). Does Place Attachment Affect Social Well-Being? Revue Européenne de Psychologie Appliquée/European Review of Applied Psychology. Vol 60: 233-238.

[20] Lewicka, M. (2011). Place Attachment: How Far Have We Come in the last 40 Years? Journal of Environmental Psychology. Vol 31: 207-30.

[21] Jack, G. (2012). The Role of Place Attachments in Wellbeing. England: Ashgate.

[22] Relph, E. (1976). Place and Placelessness. London: Pion Limited.

[23] Mathews, H. (2003). The Street as Liminal Space: The Barbed Spaces of Childhood. London \& New York: Routledge.

[24] Sobel, D. (1993, 2002). Children's Special Places: Exploring the Role of Forts, Dens, and Bush Houses in Middle Childhood. Detroit, Michigan: Wayne State University Press.

[25] Peschardt, K. K., Schipperijn, J. dan Stigsdotter, U. K..(2012)..Use of small public urban green spaces (SPUGS)..Urban forestry \& urban greening. Vol 11: 235-244.

[26] Lewicka, M. (2010). What Makes Neighborhood Different from Home and City? Effects of Place Scale on Place Attachment. Journal of Environmental Psychology. Vol 30: 35-51. 
[27] Williams, D. R. dan Vaske, J. J. (2003). The measurement of place attachment: Validity and generalizability of a psychometric approach. Forest Science. Vol 49: 830-840.

[28] Shamai, S dan llatov, Z. (2005). Measuring Sense of Place: Methodological Aspects. Tiidschrift voor economische en sociale geografie. Vol 96: 467-476.

[29] Morgan, P. (2010). Towards a Developmental Theory of Place Attachment. Journal of Environmental Psychology. Vol 30: 11-22.

[30] Ji, Z. (2009). A Study of Place Attachment: The Case of Public Housing Residents and Neighborhood Parks. Dissertation. Architecture Program. Singapore: National University of Singapore.

[31] Day, C. (2007). Environment and Children: Passive Lessons from Everyday Environment. Burlington, MA: Architectural Press.

[32] Prakoso, S. (2015). Place Habit sebagai Fenomena Kehadiran Kelekatan Anak pada Tempat. Disertasi. Program studi Arsitektur. Depok: Universitas Indonesia.

[33] Manzo, L. C. dan Perkins, D. (2006). Finding Common Ground: The Importance of Place Attachment to Community Participation and Planning. Journal of Planning Literature. Vol 20: 335-350.

[34] Jack, G. (2008). Place Matters: The Significance of Place Attachments for Children's Well-Being. British Journal of Social Work. Vol 40: 755-771.

[35] Lekies, K. S. (2011). Connection to Place: Exploring Community Satisfaction and Attachment Among Rural Youth. Children, Youth and Environments. Vol 21: 77-99.

[36] McKendrick, J. H., Bradford, M. G. dan Fielder, A. V. (2000). Time for a Party! Making Sense of the Commercialisation of Leisure Space for Children. London \& New York: Routledge.

[37] Chistensen, P. dan O'Brien, M, (2003), Children in the City: Introducting New Perspective. London \& New York: Routledge. 